\title{
A Systematic Method to Analyze Force Majeure in Construction Claims
}

\author{
Saud Alshammari ${ }^{1, *}$, Khalid Al-Gahtani ${ }^{1}$, Ibrahim Alhammad ${ }^{1}$ and Nuhu Braimah ${ }^{2}$ \\ 1 Department of Civil Engineering, King Saud University, P.O. Box 2454, Riyadh 114, Saudi Arabia; \\ kgahtani@ksu.edu.sa (K.A.-G.); alhammad@ksu.edu.sa (I.A.) \\ 2 Department of Mechanical, Aerospace, and Civil Engineering, College of Engineering, Design and Physical \\ Sciences, Brunel University, Uxbridge, Middlesex UB8 3PH, UK; nuhu.braimah@brunel.ac.uk \\ * Correspondence: saudayid@gmail.com
}

Received: 13 October 2017; Accepted: 30 November 2017; Published: 5 December 2017

\begin{abstract}
In construction delay claims, force majeure is normally recognized as an excusable risk that entitles contractors only to time extensions, but neither of the contracting parties is entitled to monetary compensation to recover delay damages. However, there are instances where contractors are entitled to both time and cost compensations, as evidenced by some court cases relating to force majeure claims. Such instances involve attributing the occurrence of the force majeure to the effect of other prior delay events that pushed project performance into the period of the force majeure. Existing delay analysis methods are not capable of addressing this issue, as none take the impact of other delays into consideration when analyzing force majeure claims. Stimulated by this gap, this study proposes an improved and sound method for fairly analyzing the responsibility of force majeure delay claims amongst contracting parties. This method was implemented on a case project to help demonstrate its application and also ascertain its practicability. The contribution of this paper is twofold. First, it has highlighted the situation of force majeure delay that can be compensable, creating more awareness among researchers and industry practitioners. The second is a proposed systematic process to appropriately analyze its responsibility, which equitably addresses claims from such delays with little or no chance of dispute ensuing.
\end{abstract}

Keywords: construction delays; force majeure; entitlement; delay claims; excusable non-compensable delay

\section{Introduction}

Delay in construction projects is one of the most recurring issues and common problems in construction claims [1]. If a project is not completed on time, an owner's lost profits and financing costs can add up quickly. Similarly, a contractor will expend significant amounts in lost opportunities and extended performance costs [2]. Due to this issue, and with the increasing size and complexity in nature of projects, construction claims have received much attention recently as a result of the increasing number of delay disputes [3]. Therefore, construction delay claims have received more considerable efforts aimed at enhancing delay claim settlements and reducing the high level of disputes [4-6]. This includes the needs for improvement which can reduce the impact of delay analysis issues and increase the efficiency of delay analysis techniques (DATs) $[7,8]$. However, there are several issues that have a potential impact on the delay analysis results, which have not been considered in the delay analysis [9], especially when the external events are involved in the construction delay claims.

The recent natural disasters and extreme weather have resulted in an increase of delay claims and have raised complex issues relative to force majeure clauses [10-12]. In construction contracts, these events, and other events that have been stipulated in force majeure clauses, would exclude liability where unforeseen events, beyond a party's control, prevent the performance of its contractual obligations, meaning that the contractor is entitled to extra time to perform without monetary 
compensation [13]. Though force majeure delays are not considered to be compensable, the common denominator in force majeure case law involves the evaluation of essential evidence for undertaking precautions and reasonable preparation to avoid the consequences of a foreseeable condition. It is not sufficient to merely contend that the delay resulted from a severe storm or hurricane. Therefore, it should be kept in mind that it is possible for a force majeure delay to be compensable to the innocent party suffering damages [14].

With a lack of understanding of the real aspects involved with compensation situations for force majeure delay, the liability for force majeure poses great difficulty to practitioners in delay claim resolution. Although it has been stated that a delay that would ordinarily be non-compensable may be transformed into a compensable delay [15] (pp. 1-11), this is not popular in delay analysis. For example, a case of force majeure delay that would not have occurred to the schedule if the project would have been completed during the original contract period is a situation in which force majeure can demand compensation. This case of force majeure claims was found in the subject of disputes for delay claims [16-18], wherein the owner's delay extended the completion date of the overall project and pushed a contractor's performance into an unusually severe weather period. The effects of the owners' contributions in forcing the contractor's performance into the force majeure period were taken into consideration. Thus, compensation for delay damages resulting from the delays of winter weather was awarded to the contractors. The rationale for this decision was based on the fact that the force majeure delay was caused solely by delays on the part of the owner, which were beyond the control of the contractors.

The above decision to grant compensation for this situation of force majeure delay raises a number of issues. First, this issue has not been discussed in practical use of delay analysis. Second, this issue has not been considered in DATs, which could affect the analysis results. Finally, the responsibility for pushing the performance into the force majeure period could result from multiple parties, which needs a proper analysis approach that can determine its liability. There are many excellent papers and law review articles that address the concept of force majeure in construction contracts [19], or in the context of comparative legal systems [20,21], which is beyond the scope of this study. This paper intends to discuss contracting parties' interference in extending project performance into force majeure periods. In pursuit of this objective, the paper provides a framework and systematic method for resolving the liability for force majeure delays in construction claims. This represents the gap in literature for which the authors have sought to contribute an up-to-date knowledge to ensuring fairness resolution of delay claims.

\section{Literature Review}

In construction delay analysis, there are generally three types of delays that occur on construction projects. The types of delays have been labeled as (1) non-excusable (NE) delays, which are attributed to the action of the contractor. These are the delays that do not entitle the contractor to either a time extension or the recovery of delay damages-the contractor may be held liable for the owner's delay damages due to this delay; (2) excusable compensable (EC) delays can be delays that are owner-caused, which typically entitle the contractor to both a time extension and delay damages; (3) excusable non-compensable (EN) delays are delays that are not the fault of the owner or the contractor, which are the delay events that allow the contractor to an extension of time for the whole period of delay but is not allowed damages for delay-related costs. Also, the owner is required to extend the project for the same time as that of the delay, without the right to late completion damages [22-25]. It should be noted that EN delay is typically the delay that results from force majeure events, which excuses the liability from extending the contract time but without compensation.

Depending on the terms of the construction contract, force majeure delay may include unforeseen events with causes beyond the control of the parties such as fires, earthquakes, floods, hurricanes, abnormally severe weather, freight embargoes, war, acts of the public enemy, acts of the government in its sovereign capacity or change of law or regulation, and other natural disasters. Such events 
prevent the parties from fulfilling their obligations under the contract. As the impact of these events on delaying the project performance means that only the contract completion date is extended for a period equal to the impact period, without monetary compensation to either of the contracting parties [13,19-21]. However, there are some circumstances where the parties' action may transform a force majeure delay that would ordinarily be non-compensable into a compensable delay.

For example, some delay claims experts have emphasized that "a delay that could have been avoided by due care of one party is compensable to the innocent party suffering damages as a result of the delay's impact" [15] (pp. 1-10-1-12). This means that if a non-compensable delay resulted solely from the delay of a party, the opportunity of delay damages would be recoverable by the other party. This issue of recovery of delay damages on account of an adverse weather delay claims has notably been addressed by the Armed Services Board of Contract Appeals (ASBCA) in the Appeal of DTC Engineers \& Constructors. DTC's claim was based on severe weather delays, for which the normal remedy under the force majeure clause is time extension, but not money. Consequently, the ASBCA found that the adverse weather claim was "not grounded" in the force majeure clause, but instead was based on a constructive suspension of work by the Government under the Suspension of Work clause. Finally, the ASBCA held open the possibility of money damages, stating that "government delays which pushed a contractor's performance into periods of adverse weather can be a cause of additional delay for which a contractor may be compensated" [17]. Also, a similar case was advanced in Charles G. Williams construction claims [18]. In this case, the government characterized the claim as one based on unusually severe weather for which no responsibility for monetary compensation was due. The contractor argued the theory that the weather delays were directly caused by the government's delay, which is to say that, "had the government not suspended work on the project, the weather delays would not have occurred". The Board, however, found that weather interfered with work that would have been completed earlier under better weather conditions and that the delay was caused by the government's delay. The ASBCA agreed with that analysis, finding that the suspension of work was the direct cause of the additional weather related delays, and therefore granted money damages to the contractor.

In spite of many contributions in the subject of delay claims, proper analysis of delay claims which take into consideration the effect of a number of scheduling and delay issues is often lacking in practice [26-28]. Existing DATs are widely used in practice to help with successful claim resolutions [29,30], but they do not account for the responsibility of extending project's performance into force majeure periods. This is due to lack of awareness of the issue in delay analysis, coupled with the paucity of such claims in construction litigation. To address this gap, this paper considered various dimensions of this issue, as presented in the following sections, to overcome this issue as long as the events of force majeure have been increased globally [31-33].

\section{Force Majeure in Construction Delay Claims}

Force majeure clause in construction contract exclude liability where unforeseen events prevent the performance of its contractual obligations. The term "force majeure" is principally identified as being an "exceptional" event or circumstance, beyond the party's control, and something that it could not have reasonably been provided against before entering into the contract. Further, the event cannot be one that the party could have reasonably avoided or overcome, nor is it allowed to be "substantially" attributable to the other party. This means that, when the force majeure event falls into the above criteria, the contractor is entitled for time extension but neither party is entitled to a monetary claim [34-37].

Although practitioners share the common concept that a delay due to force majeure is often classified as EN delay [38], this contradicts many force majeure claims that have concluded in a compensation for force majeure delays $[10,11,19-21,31]$. This is due to the fact that the determination of delay responsibility and the recovery of delay damages will depend on the facts surrounding the claim, certain measurements for determining the real delay cause, and proper analyses for 
allocating its responsibility [39]. Thus, ignoring the real reason for its occurrence raised interesting and complex issues when preparing or analyzing the force majeure claim [14-18]. In this regard, very little improvements have been reported in construction claims for force majeure delay analysis [40-42], which have not helped with reducing force majeure disputes in the construction industry.

Although there is no place for recovering any damages when the force majeure delay meets the above criteria, the occurrence time for the force majeure event during the contractual periods is however an important criterion that should not be neglected when determining the entitlements that ought to be granted to the affected parties. To clearly illustrate this criterion, Figure 1 shows two different scenarios for force majeure delay on the schedule. In Scenario I, force majeure delay (FMD) occurred during the original contract period. For Scenario II, FMD occurred in the delayed period after the original contract period. In both scenarios, FMDs have occurred on the schedule and caused a delay to the project performance due to different reasons, as follows.

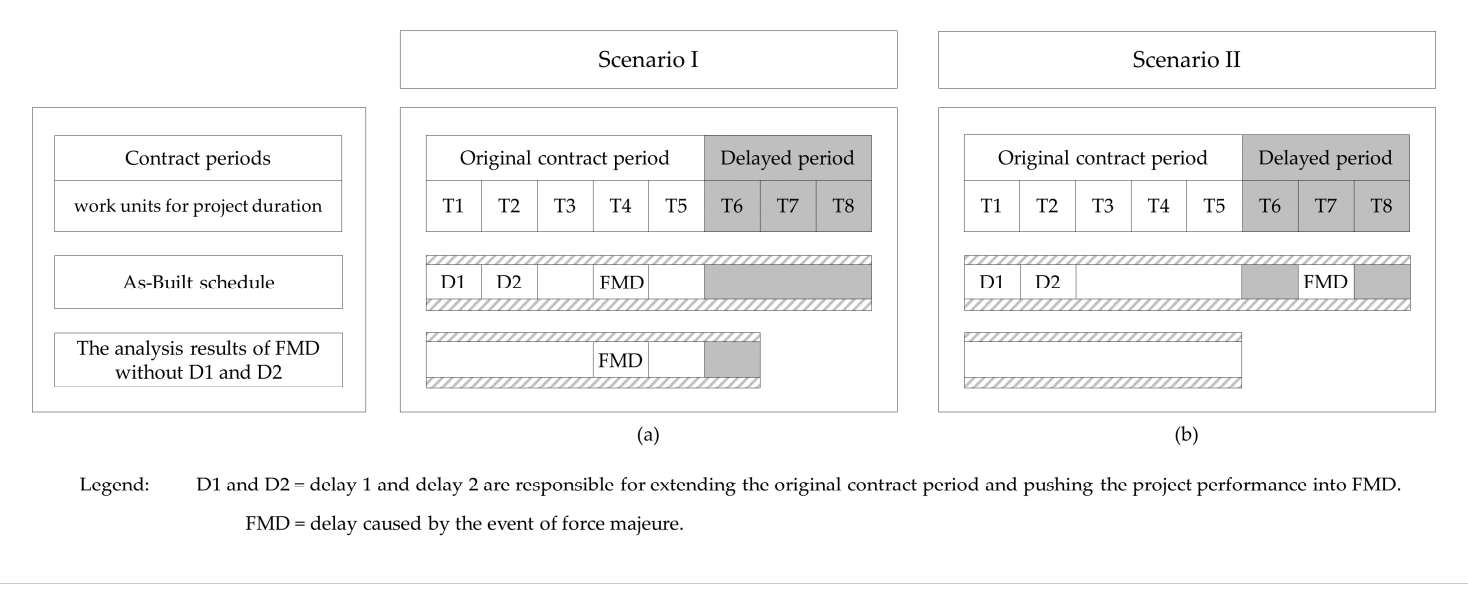

Figure 1. The two timings for the occurrence of force majeure delay during the contractual periods.

In Scenario I, case (a) shows FMD, for e.g., a natural disaster period, that occurred at T4. Obviously, this type of delay lies beyond the reasonable control of all the parties. Also, FMD in this scenario happened during the original contract period that was agreed upon among the contract parties. Based on its occurrence time being within the contractual period, there is no causal relationship between the FMD and other delays. This means, with or without the prior delay events, D1 and D2, the FMD delay would still affect project progress at T4. In this case, FMD is typically unavoidable by the exercise of ordinary care. This situation offers a legitimate excuse under most force majeure clauses, where the normal remedy entitles a contractor to an additional time to complete the contract but with no additional money. For the purpose of this study, such condition of force majeure delay occurrence is referred to hereafter as unavoidable force majeure delay (UFMD).

In Scenario II, the case is completely different. Case (b) shows the FMD to have occurred at T7. In this scenario, D1 and D2 have contributed to the extending of the original contract period into T7, where the force majeure occurred. Thus, the FMD is the result of the delays to the original contract period. Without the prior delays, D1 and D2, the project would have been completed at T5. This situation is similar to DTC's claims case, of which it was concluded that "had the Government not suspended work on the project, the weather delays would not have occurred" [17]. Thus, when a party's action (or inaction) is the cause of pushing a project's performance into a force majeure delay, the latter may be deemed a compensable delay [15-18]. Therefore, the occurrence of FMD in this case would have to be treated completely different from case (a). Scenario II also illustrates the fact that the force majeure delay that occurred after the original contract period was a preventable delay in the sense that it would not have been an issue had the project been completed during the original contract 
period. For the purpose of this study, such FMD is referred to hereafter as preventable force majeure delay (PFMD).

In general, UFMD and PFMD seek to explain a delay risk for unforeseeable events and its measurement of its liability from the perspective of avoiding or preventing its occurrence time. The current practice for dealing with delay claim analyses recognize only the UFMD scenario, with the usual remedy to contractors being the granting of time extensions only. This delay scenario is an unavoidable risk situation under the exercise of due care of neither party by virtue of its occurrence during the contract period that has been mutually agreed upon among the parties. Generally, the possibility of preventing the delay risk during the project course is a major factor for determining where its liability will fall. In line with risk allocation principles employed in construction delay claims, the theory of the PFMD in this study is underpinned by the legal judgements of forensic schedule analyses for a specific scenario of force majeure delay that has been the subject of the dispute between contracting parties in several court cases (see cases cited in [16-18]). This scenario is hardly accounted for in delay analysis practice, in spite of the fact that court cases have clearly attested to its legitimacy. It is not surprising that the cited cases recognized such entitlements, as the rationale for the decisions largely follow the principles of the risk assessment for avoiding and preventing the delay. As depicted in Figure 1, preventing the project from delaying the original contract time would precisely have prevented the occurrence time of PFMD. Therefore, PFMD can rightly be classified as a "preventable" delay situation on account of the fact that it purely brought by the consequences of extending the original contract time, which could have been avoided by meeting the original contractual deadline.

\subsection{Unavoidable Force Majeure Delay (UFMD) and Preventable Force Majeure Delay (PFMD) in Construction Litigation}

As illustrated in the above, the occurrence time of force majeure delays, whether before or after the original date of project completion, will determine its type, whether it is a UFMD or PFMD. Both UFMD and PFMD have the potential of impacting both the schedule performance period and the overall cost of the project. For this reason, the analysis should take various principles for analyzing their entitlement. In the case of UFMD, the entitlement is typically an extension of time only as the usual remedy for force majeure delays. The concept in this entitlement is that, since the cause of this delay was beyond the parties' control and without the fault or negligence of neither party, then neither party should benefit or be damaged. Therefore, the owner is required to extend the time of performance of the work and give up the right to late completion damages for the time resulting from this delay.

In contrast, the PFMD has occurred on the schedule only due to the extension of the original contract period. Since the original contract time for the project was supposed to be completed before the period of PFMD, one of the contracting parties at least is therefore responsible for delaying the original contract period and pushing the performance into PFMD period. Thus, the innocent party suffering damages has the right to claim against any delay that resulted from the negligence or tardiness of the other party [15] (pp. 1-4). In this case, the attitude typically expressed by the innocent party is, "why should I carry such expenses or lost profit when the other party's action has extended the project performance into this period of delay?" The argument, when analyzed in the legal context of delays, is that completing the project during the original contract time would avoid such delay damages.

\subsection{UFMD and PFMD in Existing Delay Analysis Techniques (DATs)}

Determining the contractual responsibility of delay is the most likely source of dispute in construction projects. Thus, DATs are applied to prepare the logical basis to persuade parties claims concerning the extension of time and financial burden. More precisely, delay analysis refers to a forensic investigation into the issue of what has caused a project to run late, for the purpose of establishing lines of investigation and demonstrating entitlement. Delay analysis methods must provide logic of 
cause and effect relationship for identifying what events contributed to delay and what is the effect of each event [43].

This has generated considerable initiatives from researchers and industry practitioners aimed at enhancing the application of existing DATs. In spite of the many contributions $[9,27,29]$, proper analysis of delay claims which take into consideration the effect of a number of scheduling and delay issues is often lacking in practice. By reviewing the existing DATs, these techniques range from less accurate to very accurate, depends on their capabilities and limitations in practical use [44-50]. However, the techniques based on the critical path method (CPM) are suitable for creating more rigorous results. These techniques include impacted as-planned, time impact, windows analysis method, and total float management [51-61].

Among the CPM techniques, the window analysis method has shown a capability for resolving most delay analysis issues. The window analysis method has been found to be the most widely used and popular for delay analysis. This method can also resolve the issue of concurrent delays in delay claims $[27,50,62]$. Also, it offers better accuracy of the results if the analysis used more snapshots or a daily window $[9,29]$. However, the window analysis method does not consider the issue of PFMD in its analysis process. Also, none of the existing DATs have taken the issue of PFMD in its analysis process. Therefore, it is noteworthy that the need for analysts to take the issue of PFMD into account in their delay analysis is becoming an increasingly vital requirement, since it exists in legal judicial claims which do not consider this issue in the existing DATs.

\section{Research Methodology}

Since time translates into money, it is very important to assign the responsibility for PFMD in a manner that is equitable to the owner and the contractor before any economic damages are determined. Resolving the issue of PFMD is therefore of crucial importance if delay claim disputes among contracting parties are to be minimized. In the absence of the consideration of PFMD issues by existing DATs, the need for proper and fair analysis method for calculating the schedule delays that addresses PFMD responsibility issues is highly warranted. Therefore, the objective of this paper is to propose an appropriate method that will help ensure such transparency in delay analysis, and to also protect the right of contracting parties from lost profits or benefits through unfair delay claims analyses.

In this regard, the author's research approach included first the conducting of a critical review of literature from both technical and legal materials in the field of engineering and construction project disciplines. The technical materials researched included technical papers and articles, construction delay analysis textbooks, and mathematical formulas for computing delay claims. Legal materials researched included case law, construction delay claims and legal textbooks. The purpose of this review is to establish, among others, the state of the art on the subject of delay analysis, by investigating (1) the existing delay analysis issues that can affect the accuracy of the analysis results; (2) the capability of the existing DATs, in addressing the delay issues of relevance to claims parties; and (3) an appropriate methodology for addressing PFMD issues in delay analysis that can help claims analysts, judges and jury members, lawyers, contractors, and owners in construction industry.

Conclusions from the reviews include the fact that many techniques have been developed over the years to measure and analyze delays in a project schedule. Many of these techniques do not consider many of the delay analysis issues such as changes in critical path(s) and concurrent delays. Among existing DATs, the window analysis method is adjudged or known to have the capability to resolve most of the delay issues and present the most robust analyses and accurate results. However, the issue of PFMD responsibility is completely ignored and not been taken into account in window analysis method, as well as in the other existing DATs, which makes the analyses less comprehensive and less accurate in the apportionment of delay responsibility.

The method devised for calculating such schedule delay analysis is based on the following three main steps. First, it requires determining the critical delays that caused delays to the overall completion of the project, taking into account most of the delay analyses issues. Second, it requires employing 
a procedure to determine UFMD and PFMD among the critical project delays. Finally, it requires an appropriate method for resolving the responsibility of the critical PFMDs. Although the analysis of the critical PFMD responsibility is usually a straightforward process when only one party is responsible for extending the original contract period, it can be a very difficult undertaking when various parties create delays that contribute to extending the original contract time into PFMD period. In this case, the analysis should not neglect any delay impacts that contribute to extending the original contract time into each period of PFMD.

The proposed improved methodology addresses the first step using the window analysis method, which offers the most accurate results in determining critical project delays. The procedures for running window analysis have been extensively described in the literature (see, for example, $[29,47,50-53]$ ), and therefore will not be discussed any further in this paper. For the last two steps of the methodology requirements, it is significant to develop an appropriate and dedicated method for resolving the issue of PFMD responsibility.

\subsection{Systematic Method for Calculating Schedule Delay with Considering PFMD}

The proposed systematic method that can be used for the schedule delay analysis involves the integration of the window analysis method with a dedicated method for analyzing the aspect of PFMD responsibility issue. Like the window analysis method, this new PFMD method makes use of a daily analysis approach to track the impact of each delay in pushing the project into the PFMD period. The dedicated method is therefore a detailed methodical analysis aimed at calculating the responsibility of each delay event in consuming the real time to the period of PFMD occurrence. The idea of this proposed systematic method is to bring together the benefits of the two approaches for analyzing the schedule delays which adequately considers the most delay issues, as well as resolving PFMD responsibility.

In addressing PFMD issues in delay analysis, the process would require a large amount of information to undertake a thorough analysis. Figure 2 shows the key inputs data for the proposed analysis method as including as-panned and as-built schedule with the listing, timing, and span of all of the delay events. It involves eight orderly processes of a methodical procedure. The proposed system's output is the responsibility of the project delays that are responsible for extending the project completion with considering the PFMD issue.

In this study, the proposed method focuses on the determination of how actual delay events on a project occurred and interacted in the context of a schedule model, for the purpose of understanding any deviation from a planned schedule and the role of such deviation into other delays within the project. Therefore, the execution of the proposed method first starts with the window analysis method to determine the critical delays. The dedicated method is then implemented by first classifying the critical force majeure delays into UFMD and/or PFMD, based on the period of their occurrence, whether before and/or after the original completion date, respectively. The daily analyses are then performed for each period of PFMD in a chronological order. For the first PFMD period, the affected activity by the PFMD is first identified. The analysis then starts by impacting the baseline schedule with the delay events day-by-day to track the early finish of the affected activity before and after the impact. It aims to calculate the loss of time between the original early finish of the affected activity and the period of PFMD occurrence, which will determine the impact of each delay event and its responsibility into the selected PFMD period. Extending the early finish (EF) of the affected activity into PFMD occurrence time by the delay event is the indicator of the delay being responsible or not. The original EF of the affected activity therefore have been used in this method to discover (1) how much time was between the period of PFMD occurrence and the original EF of the affected activity; and (2) which of the schedule delays are solely responsible for consuming that time. Also, the method takes into account that the PFMD periods that have been resolved will not be neglected in determining the responsibility for any following PFMD period. In order to ensure clarity on the use of the proposed method, the eight orderly processes that need to be carried out are presented as follows. 


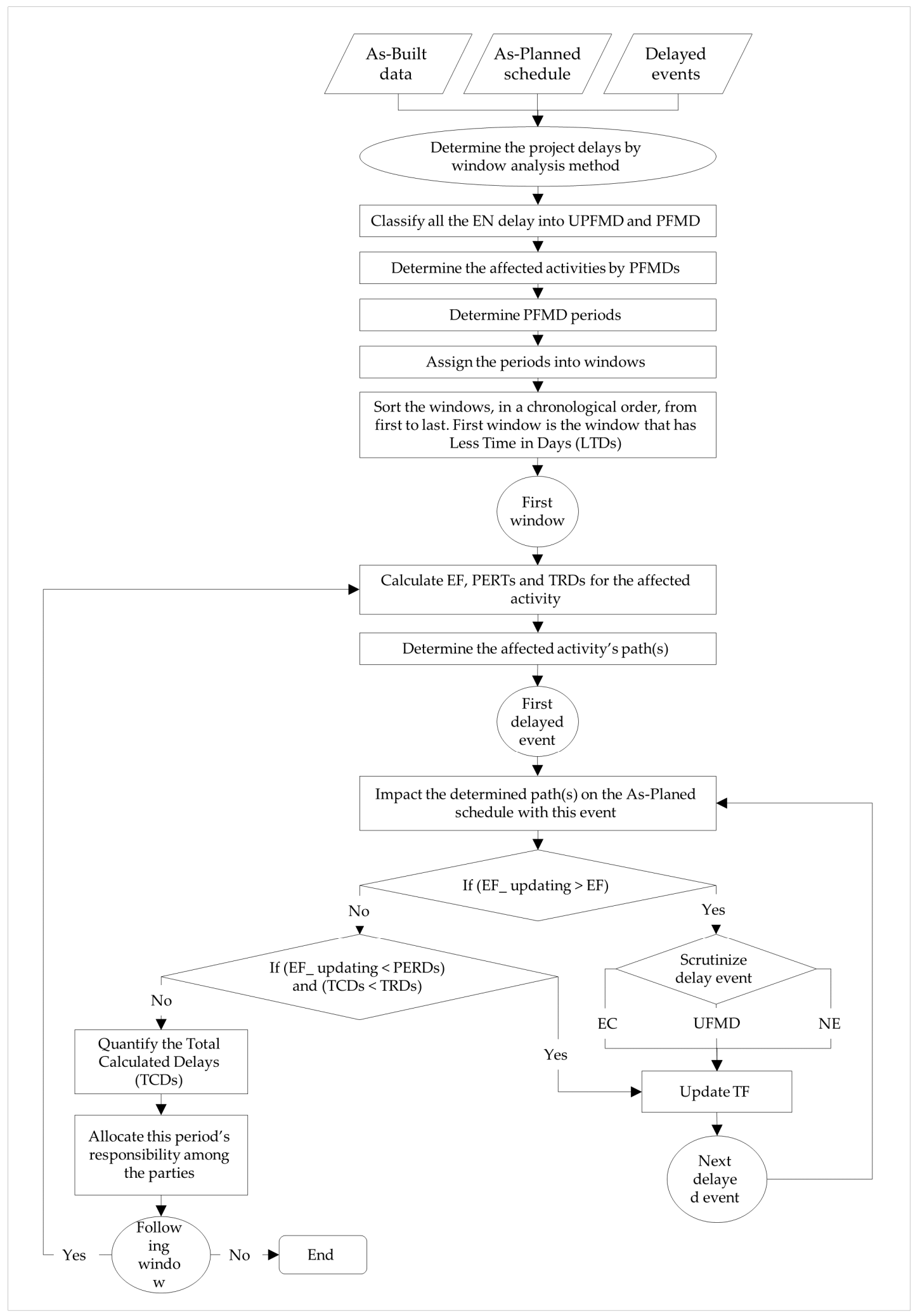

Figure 2. The flowchart of the proposed method.

1. Analyze the schedule for identifying project delays by window analysis. The final analysis gives the total (EC, NE, and EN) that represent the responsibility for the total project delay to each party (owner, contractor, and neither party), respectively. 
2. Distinguish the extension period of the project contract. The extension period is the difference in the period between the original completion date and the actual completion date of the project, as in Equation (1):

The extension period $=($ As-built project duration $)-($ As-planned project duration $)$,

3. Determine (from as-built schedule and as the results of the daily window analysis) the following:

- $\quad$ EN delay(s) that occurred during as-planned duration and classify this event(s) as UFMD(s).

- EN delay(s) that occurred during the extension period and classify this event(s) as PFMD(s).

- List the project delays, as transformed from (EC, NE, and EN) into (EC, NE, UFMD, and PFMD).

4. Determine (from the as-built schedule) PFMD(s) and locate them on the as-planned schedule (insert them at the pathway of affected activity in the actual day of its occurrence).

5. Define PFMD period(s). Any PFMD event or series events of PFMD that have a sequential order, without any interrupted of other delay type or work continuation, and affected the same activity forms one period of PFMD(s). For each period, define also the activity that has been affected by $\operatorname{PFMD}(\mathrm{s})$.

6. Assign each defined period into a separate window. Determine also in each window the first day window (FDW) and last day of window (LDW), which FDW and LDW are the first day and last day, respectively, of PFMD in each defined period. Also, sort the windows in a chronological order from first to last. The first window is the window that has less time in days (LTDs) to the as-planned completion date. In case of having two or more windows that have the same LTDs, any of them could be first in this window. LTDs can be counted using Equation (2):

$$
\text { LTDs }=\text { FDW }- \text { As-planned project duration } \text {. }
$$

7. Analyze period ( $\mathrm{t})$, as the following steps:

- $\quad$ Step 1: Insert only the first window into as-planned schedule, then this schedule becomes the updated as-planned schedule. Determine $\sum$ PFMD during period $(t)$, which is the total PFMDs in this period.

- Step 2: From the as-built schedule, determine the activity's path(s) that is affected by period ( $\mathrm{t}$ ).

- Step 3: Calculate early finish (EF) of the affected activity form the updated as-planned schedule, as an Equation (3):

$$
\mathrm{EF}=\text { the affected activity duration }+\mathrm{EF} \text { of predecessor activity, }
$$

- Step 4: Calculate the period end to the responsible delays (PERDs) for period ( $t$ ), as in Equation (4):

$$
\text { PERDs }=\text { LDW of period }(\mathrm{t})+1 \text {, }
$$

- Step 5: Calculate total responsible delays (TRDs) in period ( $\mathrm{t}$ ), as an Equation (5):

$$
\mathrm{TRDs}=\mathrm{FDW}-\mathrm{EF},
$$

- Step 6: From the as-built schedule, insert, into the updated as-planned schedule, first day of delay event(s) that only occurred on the path(s) of the activity that affected by period (t).

- Step 7: Update the delay's impact on the updated as-planned schedule. Then this schedule become (The impacted as-planned schedule)

- Step 8: Calculate the updating Early Finish (EF_ updating) of the activity that affected by period ( $t$ ), Equation (3) can be used, then the delay's impact can be 
- $\quad$ Step 9: Compute the delay event according to Equation (6):

$$
\text { If }\left(\mathrm{EF}_{-} \text {updating }>\mathrm{EF}\right) \text {, otherwise step 11, }
$$

- $\quad$ Step 10: Classify this delay event as EC, NE, or UFMD.

- $\quad$ Step 11: Compare (EF_ updating) with and PERDs, according to Equation (7):

$$
\text { If (EF_ updating < PERDs) and (TCDs < TRDs) then step 12, otherwise step 14, }
$$

- Step 12: Update the next analysis as that: (EF to be $\mathrm{EF}_{-}$updating) of the activity that affected by period ( $\mathrm{t})$; (the impacted as-planned schedule) to be (the updated as-planned schedule), and (the following) day of delay event(s) that occurred only on this path(s) become (the first) day of delay event(s).

- Step 13: Return to Step 7.

- Step 14: Quantify the total calculated delays (TCDs), as in Equation (8):

$$
\mathrm{TCDs}=\sum \mathrm{EC}+\sum \mathrm{NE}+\sum \mathrm{UFMD},
$$

- Step 15: Allocate the responsibility of period ( $\mathrm{t}$ ) among the parties by using Equations (9)-(11) for calculating the owner's responsibility, contractor's responsibility, and neither party's responsibility, respectively.

$$
\begin{aligned}
& \left(\frac{\sum \text { EC responsible for period }(t)}{\sum \text { TCDs responsible for period }(t)}\right) * \sum \text { PFMD during period }(t) \\
& \left(\frac{\sum \text { NE responsible for period }(t)}{\sum \text { TCDs responsible for period }(t)}\right) * \sum \text { PFMD during period }(t) \\
& \left(\frac{\sum \text { UFMD responsible for period }(t)}{\sum \text { TCDs responsible for period }(t)}\right) * \sum \text { PFMD during period }(t)
\end{aligned}
$$

- Step 16: Assign the result of period ( $t$ ) to the responsible party(ies), where the result assigns to EC, NE, and UFMD for the total project delays.

- Step 17: Determine the following window to become period $(t)$ and return to step 9 of this procedure); otherwise process No. 8.

8. Quantify the total project delays to the responsible parties.

\subsection{Case Study}

In order to evaluate the proposed method more thoroughly, a test case was designed and simulated with various construction delay scenarios. It involves a construction of a project that has 14 activities and is affected by the most common scheduling issues. The idea behind designing this case-study is to show obviously a particular situation where the effect of the parties' delays extends the project performance into PFMDs, as shown in DTC's claim [17]. Though the proposed methodology has the capability to be used in delay analysis processes for real-life projects, it however involves a large amount of processes and information that exceeds the limited space for this paper, as well as a calculation procedure that would be difficult to handle manually. Therefore, this case is found to be suitable to assess the approach process.

The project's as-planned schedule along with the activity, duration, and independent relationships are shown in Figure 3. The as-planned schedule indicates a total project duration of 20 days. The project started as scheduled but progress was affected by three main types of delay events: (EC) events for which the contractor is entitled to both time extensions and recovery of extra cost consequential upon the delay; (NE) events for which the contractor assumes the risks of costs and the time consequences 
involved; and finally, (EN) events which no party has control over, (e.g., acts of God). In this test case, all EN events identified are force majeure delays. The as-built schedule maintains the same activities and relationships but contains the delays as shown in Figure 4, forcing the total project duration to 40 days. The following section will explain the analysis conducted on the delay by using the method's procedure that proposed in this paper.

\begin{tabular}{|l|c|c|c|}
\hline Act. & predecessor & successor & $\begin{array}{c}\text { Acual } \\
\text { Duration }\end{array}$ \\
\hline $\mathbf{0 1}$ & - & Act. 02 & $\mathbf{5}$ \\
$\mathbf{0 2}$ & Act. 01 & Act. 03 & $\mathbf{5}$ \\
$\mathbf{0 3}$ & Act. 02 & Act. 04 & 3 \\
$\mathbf{0 4}$ & Act. 04,07 & Act. 05 & $\mathbf{4}$ \\
$\mathbf{0 5}$ & Act. 04,10 & - & $\mathbf{3}$ \\
$\mathbf{0 6}$ & - & Act. 07 & $\mathbf{5}$ \\
$\mathbf{0 7}$ & Act. 06,09 & Act. 04 & $\mathbf{5}$ \\
$\mathbf{0 8}$ & - & Act. 09 & $\mathbf{4}$ \\
$\mathbf{0 9}$ & Act. 08 & Act. 07.10 & $\mathbf{4}$ \\
$\mathbf{1 0}$ & Act. 09 & Act. 14 & $\mathbf{7}$ \\
$\mathbf{1 1}$ & - & Act. 13 & $\mathbf{3}$ \\
$\mathbf{1 2}$ & Act. 11 & Act. 13 & $\mathbf{3}$ \\
$\mathbf{1 3}$ & Act. 12 & Act. 14 & $\mathbf{6}$ \\
$\mathbf{1 4}$ & Act. 10,13 & - & $\mathbf{3}$ \\
\hline
\end{tabular}

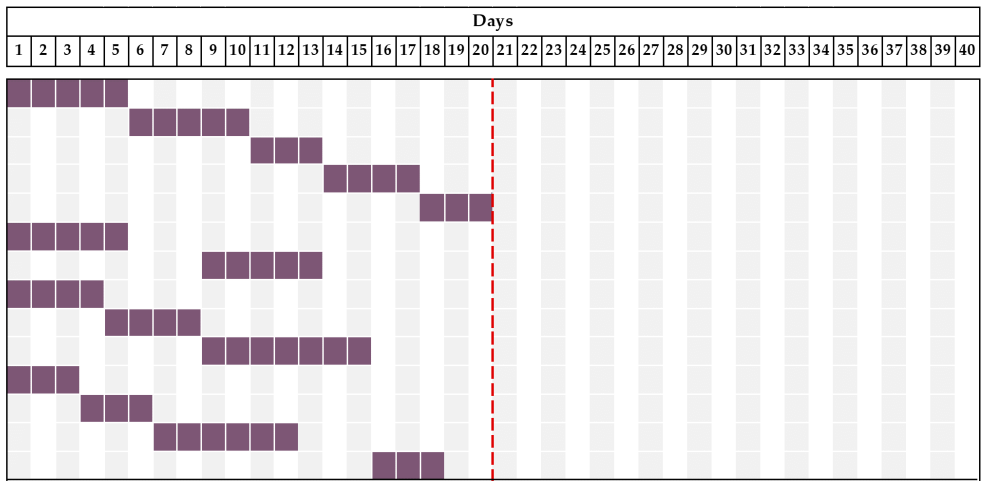

Figure 3. As-planned schedule.

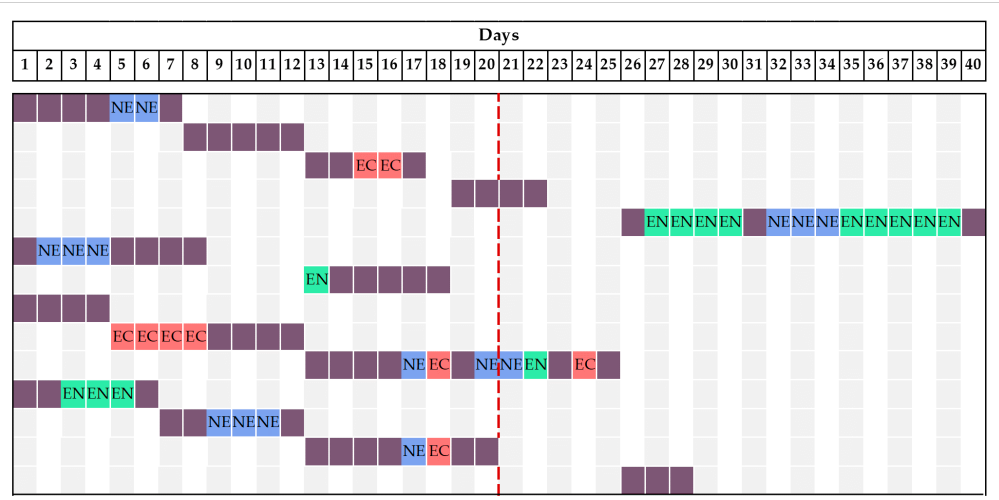

Figure 4. As-built schedule.

\subsubsection{The Analysis}

The analysis of this case study will have to follow the approach's procedures, as discussed, as follows:

1. By applying the window analysis, the total contract period was first broken into discrete time periods at days $5,6,8,13,21,22,26,30,34$ and 40 , resulting in 10 window periods. This analysis gives the same result as daily analysis. Analysis was carried out for each window successively at the various updates, as shown in Table 1 . The analysis represents an accurate and reliable results for the total project delays. The analysis shows that the project has been delayed for 20 days. The owner responsibility (EC), contractor' responsibility (NE), and neither party's responsibility (EN) are 5 days, 5 days, and 11 days.

Table 1. The results of window analysis method.

\begin{tabular}{ccccccc}
\hline Window Number & Window Periods & Schedule Update & Completion Date & EC & NE & EN \\
\hline 0 (start) & & 0 & 20 & 0 & 0 & 0 \\
1 & $1-5$ & 20 & 21 & 0.5 & 0.5 & 0 \\
2 & 6 & 21 & 22 & 0.5 & 0.5 & 0 \\
3 & $7-8$ & 22 & 24 & 2 & 0 & 0 \\
\hline
\end{tabular}


Table 1. Cont.

\begin{tabular}{ccccccc}
\hline Window Number & Window Periods & Schedule Update & Completion Date & EC & NE & EN \\
\hline 4 & $9-13$ & 24 & 25 & 0 & 0 & 1 \\
5 & $14-21$ & 25 & 26 & 0 & 1 & 0 \\
6 & 22 & 26 & 27 & 0 & 0 & 1 \\
7 & $23-26$ & 27 & 28 & 1 & 0 & 0 \\
8 & $27-30$ & 28 & 32 & 0 & 0 & 4 \\
9 & $31-34$ & 32 & 45 & 0 & 3 & 0 \\
10 (completion) & $35-40$ & 35 & 0 & 0 & 5 \\
\hline \multicolumn{7}{c}{ Tosponsibility for project delays } \\
\hline \multicolumn{2}{c}{ Total project delays }
\end{tabular}

Notes: EC: Excusable Compensable delays; NE: Non-Excusable delays; EN: Excusable Non-compensable delays.

2. By determining the extension period, as an Equation (1), the project has 20 days that extended the project time. The extension period is 20 start from day 21 up to day 40 .

3. The EN delays that occurred between day 1 and 20 are UFMDs and the others are PFMDs. Out of 11 NE delays, the project's delays involved 10 PFMDs and only one of NE delay is UFMD that effected Act.07 on day 13. Therefore, the result for this analysis is as shown in Table 2.

Table 2. The results for classifying the project delays.

\begin{tabular}{|c|c|c|c|c|c|c|c|c|}
\hline $\begin{array}{l}\text { PFMD } \\
\text { Periods }\end{array}$ & $\begin{array}{l}\text { Window } \\
\text { Number }\end{array}$ & $\begin{array}{l}\text { Window } \\
\text { Periods }\end{array}$ & $\begin{array}{l}\text { Schedule } \\
\text { Update }\end{array}$ & $\begin{array}{l}\text { Completion } \\
\text { Date }\end{array}$ & EC & NE & UFMD & PFMD \\
\hline & 0 & & 0 & 20 & 0 & 0 & 0 & - \\
\hline & 1 & $1-5$ & 20 & 21 & 0.5 & 0.5 & 0 & - \\
\hline & 2 & 6 & 21 & 22 & 0.5 & 0.5 & 0 & - \\
\hline & 3 & $7-8$ & 22 & 24 & 2 & 0 & 0 & - \\
\hline & 4 & $9-13$ & 24 & 25 & 0 & 0 & 1 & - \\
\hline & 5 & $14-21$ & 25 & 26 & 0 & 1 & 0 & 0 \\
\hline \multirow[t]{2}{*}{ (22) } & 6 & 22 & 26 & 27 & 0 & 0 & - & 1 \\
\hline & 7 & $23-26$ & 27 & 28 & 1 & 0 & - & 0 \\
\hline \multirow[t]{2}{*}{$(27-30)$} & 8 & $27-30$ & 28 & 32 & 0 & 0 & - & 4 \\
\hline & 9 & $31-34$ & 32 & 35 & 0 & 3 & - & 0 \\
\hline \multirow[t]{2}{*}{$(35-39)$} & 10 & $35-40$ & 35 & 40 & 0 & 0 & - & 5 \\
\hline & \multicolumn{4}{|c|}{ Responsibility for project delays } & 4 & 5 & 1 & 10 \\
\hline
\end{tabular}

Notes: UFMD: unavoidable force majeure delay; PFMD: preventable force majeure delay.

4. As shown in Figure 5, all PFMDs periods have been determined. On the as-planned schedule, each of the PFMD has been assigned in the actual day of their occurrence and at the pathways of affected activities.

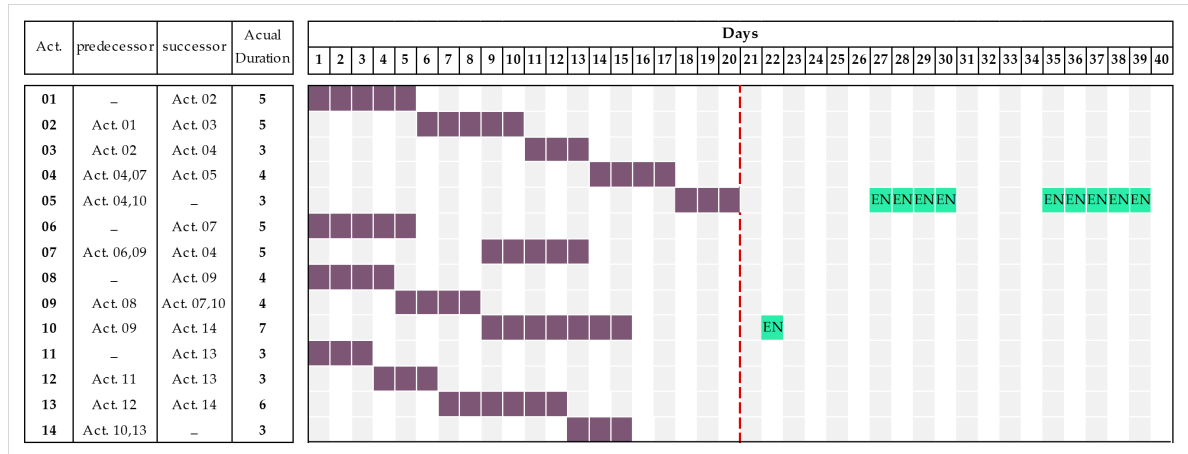

Figure 5. As-planned updated schedule. 
5. After applying the definition of a PFMD period as mentioned in step 5 of the procedure, the project has three periods. The first period is PFMD that has affected Act.10 on day 22, the second period is PFMDs that affected Act.05 between days 27-30, and the third period is PFMDs that also affected Act.05 on day 35 and continued for five days.

6. These defined periods can be breakdown into three window: window No. 1 is the first period that has FDW = Day 22, LDW = Day 22, and LTDs = Day 2.; window No. 2 is the second period that has FDW = Day 27, LDW = Day 30, and LTDs = Day 7.; window No. 3 is the third period that has FDW = Day 35, LDW = Day 39, and LTDs = Day 19.

7. Analyze period (22), as the following steps:

- $\quad$ Step 1: As Figure 3 shown, $\sum$ PFMD during period $(22)=1$ day.

- Step 2: The affected activity by period (22) is Act. 10. Therefore, the affected activity's path is Act.08-Act.09-Act.10-Act.05.

- $\quad$ Step 3: EF = Day 15 for Act.10.

- $\quad$ Step 4: PERDs = Day 22 (from the process No. 6) + 1 day= Day 23.

- Step 5: TRDs = Day 22 (from the process No. 6) - Day 15 (from Step 3 of process No. 7) $=7$ days.

- $\quad$ From Step 6 to Step 13 are as shown in Table 3.

Table 3. The analysis results for period (22).

\begin{tabular}{ccccccccc}
\hline \multirow{2}{*}{$\begin{array}{c}\text { EF of } \\
\text { Act.08 }\end{array}$} & \multirow{2}{*}{$\begin{array}{c}\text { Delay } \\
\text { Event }\end{array}$} & $\begin{array}{c}\text { Delay } \\
\text { Description }\end{array}$ & \multirow{2}{*}{ EF $_{- \text {Updating }}$} & \multirow{2}{*}{ TCDs } & \multicolumn{2}{c}{ Delay Classification } & \multicolumn{2}{c}{ Equation (7) } \\
\cline { 6 - 9 } & & & & EC & NE & UFMD & PERDs & TRDs \\
\hline 15 & 1 & Act.09 on day 5 & 16 & 1 & 1 & 0 & 0 & No \\
16 & 2 & Act.09 on day 6 & 17 & 1 & 1 & 0 & 0 & No \\
17 & 3 & Act.09 on day 7 & 18 & 1 & 1 & 0 & 0 & No \\
18 & 4 & Act.09 on day 8 & 19 & 1 & 1 & 0 & 0 & No \\
19 & 5 & Act.10 on day 17 & 20 & 1 & 0 & 1 & 0 & No \\
20 & 6 & Act.10 on day 18 & 21 & 1 & 1 & 0 & 0 & No \\
21 & 7 & Act.10 on day 20 & 23 & 1 & 0 & 1 & 0 & Yes \\
\hline
\end{tabular}

Notes: EF_ updating: updating Early Finish; PERD: period end to the responsible delays; TRDs: total responsible delays.

- $\quad$ Step 14: From Table 3, $\sum E C=5$ days; $\sum N E=2$ days; $\sum \mathrm{UFMD}=0$. Therefore, by applying Equation (8), $\mathrm{TCDs}=5+2+0=7$ days.

- Step 15: By applying Equations (9)-(11) for period (22): owner's responsibility, contractor's responsibility, and neither party's responsibility are 0.7 day, 0.3 day, and 0 , respectively.

- Step 16: The result for period (22), as Figure 6, is shown in Table 4.

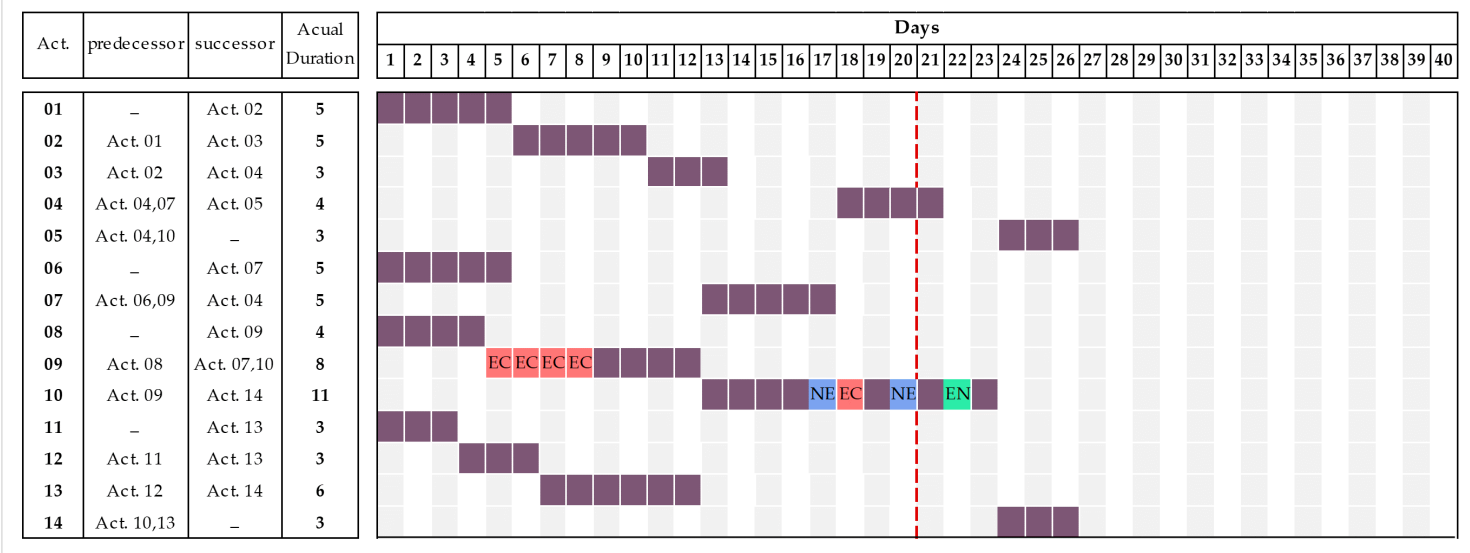

Figure 6. As-planned impacted schedule, period (22). 
Table 4. The results of period (22) into the project delays.

\begin{tabular}{|c|c|c|c|c|c|c|c|c|}
\hline $\begin{array}{l}\text { PFMD } \\
\text { Periods }\end{array}$ & $\begin{array}{l}\text { Window } \\
\text { Number }\end{array}$ & $\begin{array}{l}\text { Window } \\
\text { Periods }\end{array}$ & $\begin{array}{l}\text { Schedule } \\
\text { Update }\end{array}$ & $\begin{array}{c}\text { Completion } \\
\text { Date }\end{array}$ & EC & NE & UFMD & PFMD \\
\hline & 0 & & 0 & 20 & 0 & 0 & 0 & - \\
\hline & 1 & $1-5$ & 20 & 21 & 0.5 & 0.5 & 0 & - \\
\hline & 2 & 6 & 21 & 22 & 0.5 & 0.5 & 0 & - \\
\hline & 3 & $7-8$ & 22 & 24 & 2 & 0 & 0 & - \\
\hline & 4 & $9-13$ & 24 & 25 & 0 & 0 & 1 & - \\
\hline & 5 & $14-21$ & 25 & 26 & 0 & 1 & 0 & 0 \\
\hline \multirow[t]{2}{*}{ (22) } & 6 & 22 & 26 & 27 & 0.7 & 0.3 & - & 0 \\
\hline & 7 & $23-26$ & 27 & 28 & 1 & 0 & - & 0 \\
\hline \multirow[t]{2}{*}{$(27-30)$} & 8 & $27-30$ & 28 & 32 & 0 & 0 & - & 4 \\
\hline & 9 & $31-34$ & 32 & 35 & 0 & 3 & - & 0 \\
\hline \multirow[t]{3}{*}{$(35-39)$} & 10 & $35-40$ & 35 & 40 & 0 & 0 & - & 5 \\
\hline & \multicolumn{4}{|c|}{ Responsibility for project delays } & 4.7 & 5.3 & 1 & 9 \\
\hline & \multicolumn{4}{|c|}{ Total project delays } & & 20 & & \\
\hline
\end{tabular}

8. Analyze period (27-30), as in the following steps:

- $\quad$ Step 1: As Figure 3 shown, $\sum$ PFMD during period $(27-30)=4$ days.

- Step 2: The affected activity by period (27-30) is Act. 05 . Therefore, the affected activity has four paths, which are (Act.01-Act.02-Act.03-Act.04-Act.05), (Act.06-Act.07-Act.04-Act.05), (Act.08-Act.09-Act.07-Act.04-Act.05), and (Act.08-Act.09-Act.10-Act.05).

- $\quad$ Step 3: EF = Day 20 for Act.05.

- Step 4: PERDs = Day 30 (from the process No. 6) +1 day = Day 31.

- Step 5: TRDs = Day 27 (from the process No. 6) - Day 20 (from Step 3 of process No. 7) = 7 days.

- From Step 6 to Step 13 are as shown in Table 5.

Table 5. The analysis results for period (27-30).

\begin{tabular}{|c|c|c|c|c|c|c|c|c|c|}
\hline \multirow{2}{*}{$\begin{array}{c}\text { EF of } \\
\text { Act.08 }\end{array}$} & \multirow{2}{*}{$\begin{array}{l}\text { Delay } \\
\text { Event }\end{array}$} & \multirow{2}{*}{$\begin{array}{c}\text { Delay } \\
\text { Description }\end{array}$} & \multirow{2}{*}{$\mathrm{EF}_{- \text {updating }}$} & \multirow{2}{*}{ TCDs } & \multicolumn{3}{|c|}{ Delay Classification } & \multicolumn{2}{|c|}{ Equation (7) } \\
\hline & & & & & EC & NE & UFMD & PERDs & TRDs \\
\hline 20 & 1 & Act.06 on day 2 & 20 & 0 & 0 & 0 & 0 & $\mathrm{~N}$ & \\
\hline 20 & 2 & Act. 06 on day 3 & 20 & 0 & 0 & 0 & 0 & $\mathrm{~N}$ & \\
\hline 20 & 3 & Act.06 on day 4 & 20 & 0 & 0 & 0 & 0 & $\mathrm{~N}$ & \\
\hline \multirow{2}{*}{20} & 4 & Act. 01 on day 5 & \multirow{2}{*}{21} & \multirow{2}{*}{1} & \multirow{2}{*}{0.5} & \multirow{2}{*}{0.5} & \multirow{2}{*}{0} & \multirow{2}{*}{\multicolumn{2}{|c|}{ No }} \\
\hline & 5 & Act. 09 on day 5 & & & & & & & \\
\hline \multirow{2}{*}{21} & 6 & Act. 01 on day 6 & \multirow{2}{*}{22} & \multirow{2}{*}{1} & \multirow{2}{*}{0.5} & \multirow{2}{*}{0.5} & \multirow{2}{*}{0} & \multirow{2}{*}{\multicolumn{2}{|c|}{ No }} \\
\hline & 7 & Act.09 on day 6 & & & & & & & \\
\hline 22 & 8 & Act.09 on day 7 & 23 & 1 & 1 & 0 & 0 & $\mathrm{~N}$ & \\
\hline 23 & 9 & Act. 09 on day 8 & 24 & 1 & 1 & 0 & 0 & $\mathrm{~N}$ & o \\
\hline 24 & 10 & Act. 07 on day 13 & 25 & 1 & 0 & 0 & 1 & $\mathrm{~N}$ & o \\
\hline 25 & 11 & Act. 03 on day 15 & 25 & 0 & 0 & 0 & 0 & $\mathrm{~N}$ & o \\
\hline 25 & 12 & Act. 03 on day 16 & 25 & 0 & 0 & 0 & 0 & $\mathrm{~N}$ & o \\
\hline 25 & 13 & Act.10 on day 17 & 25 & 0 & 0 & 0 & 0 & $\mathrm{~N}$ & o \\
\hline 25 & 14 & Act.10 on day 18 & 25 & 0 & 0 & 0 & 0 & $\mathrm{~N}$ & o \\
\hline 25 & 15 & Act.10 on day 20 & 25 & 0 & 0 & 0 & 0 & $\mathrm{~N}$ & o \\
\hline 25 & 16 & Act.10 on day 21 & 26 & 1 & 0 & 1 & 0 & $\mathrm{~N}$ & o \\
\hline \multirow[t]{2}{*}{26} & 17 & Act.10 on day 22 & 27 & 1 & 0.7 & 0.3 & 0 & Ye & es \\
\hline & 17 & & 27 & 7 & 3.7 & 2.3 & 1 & 31 & 7 \\
\hline
\end{tabular}


- Step 14: From Table 3, $\sum E C=3.7$ days; $\sum N E=2.3$ days; $\sum$ UFMD $=1$ day. Therefore, by applying Equation (8), TCDs $=2.3+2.3+1=7$ days.

- Step 15: By applying Equations (9)-(11) for the period (22): owner's responsibility, contractor's responsibility, and neither party's responsibility are 2.1 day, 1.3 day, and 0.6 day, respectively.

- $\quad$ Step 16: The result for period (22), as Figure 7 shows, is shown in Table 6.

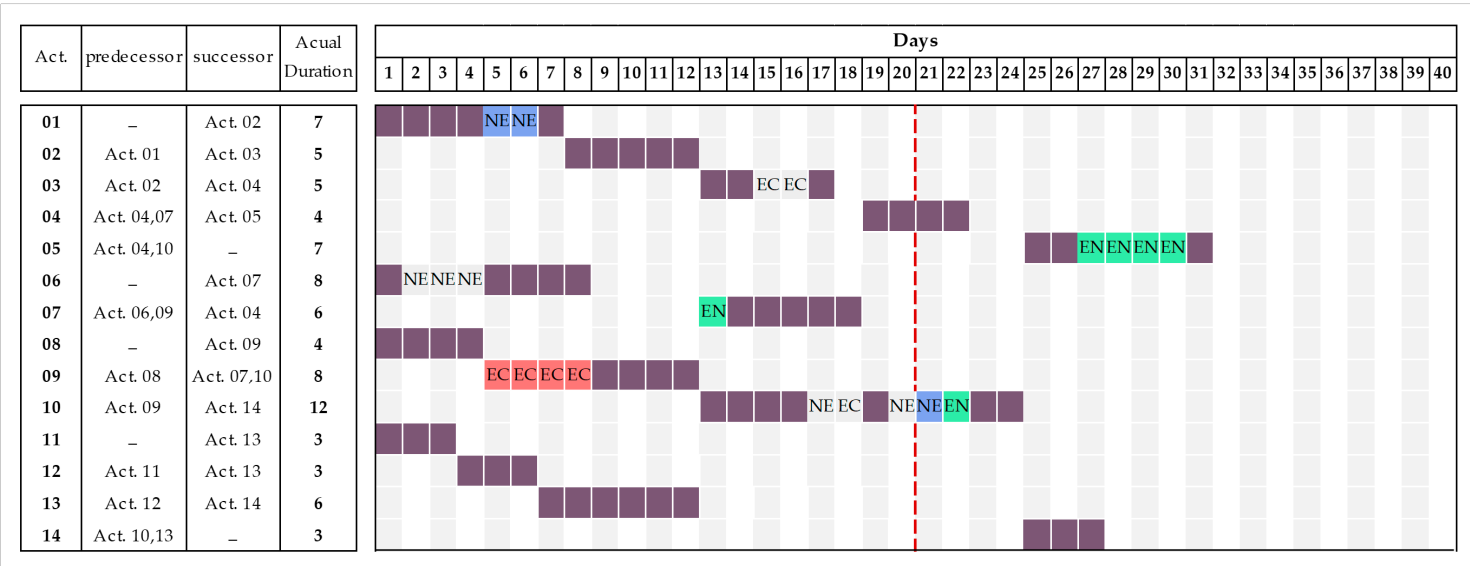

Figure 7. As-planned impacted schedule, period (27-30).

Table 6. The results of period (27-30) into the project delays.

\begin{tabular}{|c|c|c|c|c|c|c|c|c|}
\hline $\begin{array}{l}\text { PFMD } \\
\text { Periods }\end{array}$ & $\begin{array}{l}\text { Window } \\
\text { Number }\end{array}$ & $\begin{array}{l}\text { Window } \\
\text { Periods }\end{array}$ & $\begin{array}{l}\text { Schedule } \\
\text { Update }\end{array}$ & $\begin{array}{c}\text { Completion } \\
\text { Date }\end{array}$ & EC & NE & UFMD & PFMD \\
\hline & 0 & & 0 & 20 & 0 & 0 & 0 & - \\
\hline & 1 & $1-5$ & 20 & 21 & 0.5 & 0.5 & 0 & - \\
\hline & 2 & 6 & 21 & 22 & 0.5 & 0.5 & 0 & - \\
\hline & 3 & $7-8$ & 22 & 24 & 2 & 0 & 0 & - \\
\hline & 4 & $9-13$ & 24 & 25 & 0 & 0 & 1 & - \\
\hline & 5 & $14-21$ & 25 & 26 & 0 & 1 & 0 & 0 \\
\hline \multirow[t]{2}{*}{ (22) } & 6 & 22 & 26 & 27 & 0.7 & 0.3 & - & 0 \\
\hline & 7 & $23-26$ & 27 & 28 & 1 & 0 & - & 0 \\
\hline \multirow[t]{2}{*}{$(27-30)$} & 8 & $27-30$ & 28 & 32 & 2.1 & 1.3 & 0.6 & 0 \\
\hline & 9 & $31-34$ & 32 & 35 & 0 & 3 & - & 0 \\
\hline \multirow[t]{3}{*}{$(35-39)$} & 10 & $35-40$ & 35 & 40 & 0 & 0 & - & 5 \\
\hline & \multicolumn{4}{|c|}{ Responsibility for project delays } & 6.8 & 6.6 & 1.6 & 5 \\
\hline & \multicolumn{4}{|c|}{ Total project delays } & & 20 & & \\
\hline
\end{tabular}

9. Analyze period (35-39), as the following steps:

- $\quad$ Step 1: As Figure 3 shown, $\sum$ PFMD during period $(35-39)=5$ days.

- Step 2: The affected activity by period (35-39) is Act. 05. Therefore, the affected activity has 4 paths, which are: (Act.01-Act.02-Act.03-Act.04-Act.05), (Act.06-Act.07-Act.04-Act.05), (Act.08-Act.09-Act.07-Act.04-Act.05), and (Act.08-Act.09-Act.10-Act.05).

- $\quad$ Step 3: EF = Day 20 for Act.05.

- $\quad$ Step 4: PERDs = Day 39 (from the process No. 6) +1 day = Day 40.

- Step 5: TRDs = Day 35 (from the process No. 6) - Day 20 (from Step 3 of process No. 7) $=$ 15 days.

- $\quad$ Step 6 to Step 13 are as shown in Table 7. 
Table 7. The analysis results for period (35-39).

\begin{tabular}{|c|c|c|c|c|c|c|c|c|c|}
\hline \multirow{2}{*}{$\begin{array}{c}\text { EF of } \\
\text { Act.08 }\end{array}$} & \multirow{2}{*}{$\begin{array}{l}\text { Delay } \\
\text { Event }\end{array}$} & \multirow{2}{*}{$\begin{array}{c}\text { Delay } \\
\text { Description }\end{array}$} & \multirow{2}{*}{$\mathrm{EF}_{\text {- updating }}$} & \multirow{2}{*}{ TCDs } & \multicolumn{3}{|c|}{ Delay Classification } & \multicolumn{2}{|c|}{ Equation (7) } \\
\hline & & & & & EC & NE & UFMD & PERDs & TRDs \\
\hline 20 & 1 & Act.06 on day 2 & 20 & 0 & 0 & 0 & 0 & $\mathrm{~N}$ & \\
\hline 20 & 2 & Act.06 on day 3 & 20 & 0 & 0 & 0 & 0 & $\mathrm{~N}$ & \\
\hline 20 & 3 & Act. 06 on day 4 & 20 & 0 & 0 & 0 & 0 & $\mathrm{~N}$ & \\
\hline \multirow{2}{*}{20} & 4 & Act. 01 on day 5 & \multirow{2}{*}{21} & \multirow{2}{*}{1} & \multirow{2}{*}{0.5} & \multirow{2}{*}{0.5} & \multirow{2}{*}{0} & \multirow{2}{*}{\multicolumn{2}{|c|}{ No }} \\
\hline & 5 & Act.09 on day 5 & & & & & & & \\
\hline \multirow{2}{*}{21} & 6 & Act.01 on day 6 & \multirow{2}{*}{22} & \multirow{2}{*}{1} & \multirow{2}{*}{0.5} & \multirow{2}{*}{0.5} & \multirow{2}{*}{0} & \multirow{2}{*}{\multicolumn{2}{|c|}{ No }} \\
\hline & 7 & Act.09 on day 6 & & & & & & & \\
\hline 22 & 8 & Act.09 on day 7 & 23 & 1 & 1 & 0 & 0 & $\mathrm{~N}$ & \\
\hline 23 & 9 & Act. 09 on day 8 & 24 & 1 & 1 & 0 & 0 & $\mathrm{~N}$ & \\
\hline 24 & 10 & Act. 07 on day 13 & 25 & 1 & 0 & 0 & 1 & $\mathrm{~N}$ & \\
\hline 25 & 11 & Act. 03 on day 15 & 25 & 0 & 0 & 0 & 0 & $\mathrm{~N}$ & \\
\hline 25 & 12 & Act. 03 on day 16 & 25 & 0 & 0 & 0 & 0 & $\mathrm{~N}$ & \\
\hline 25 & 13 & Act. 10 on day 17 & 25 & 0 & 0 & 0 & 0 & $\mathrm{~N}$ & \\
\hline 25 & 14 & Act. 10 on day 18 & 25 & 0 & 0 & 0 & 0 & $\mathrm{~N}$ & \\
\hline 25 & 15 & Act. 10 on day 20 & 25 & 0 & 0 & 0 & 0 & $\mathrm{~N}$ & \\
\hline 25 & 16 & Act. 10 on day 21 & 26 & 1 & 0 & 1 & 0 & $\mathrm{~N}$ & \\
\hline 26 & 17 & Act. 10 on day 22 & 27 & 1 & 0.7 & 0.3 & 0 & $\mathrm{~N}$ & \\
\hline 27 & 18 & Act. 10 on day 24 & 28 & 1 & 1 & 0 & 0 & $\mathrm{~N}$ & \\
\hline \multirow{4}{*}{28} & 19 & Act. 05 on day 27 & \multirow{4}{*}{32} & \multirow{4}{*}{4} & \multirow{4}{*}{2.1} & \multirow{4}{*}{1.3} & \multirow{4}{*}{0.6} & \multirow{4}{*}{\multicolumn{2}{|c|}{ No }} \\
\hline & 20 & Act. 05 on day 28 & & & & & & & \\
\hline & 21 & Act. 05 on day 29 & & & & & & & \\
\hline & 22 & Act. 05 on day 30 & & & & & & & \\
\hline 32 & 23 & Act. 05 on day 32 & 33 & 1 & 0 & 1 & 0 & $\mathrm{~N}$ & \\
\hline 33 & 24 & Act. 05 on day 33 & 34 & 1 & 0 & 1 & 0 & $\mathrm{~N}$ & \\
\hline \multirow[t]{2}{*}{34} & 25 & Act. 05 on day 34 & 35 & 1 & 0 & 1 & 0 & Y & \\
\hline & 25 & & 35 & 15 & 6.8 & 6.6 & 1.6 & 40 & 15 \\
\hline
\end{tabular}

- $\quad$ Step 14: From Table 3, $\sum E C=3.7$ days; $\sum N E=2.3$ days; $\sum U F M D=1$ day. Therefore, by applying Equation (8), TCDs $=2.3+2.3+1=7$ days.

- $\quad$ Step 15: By applying Equations (9)-(11) for period (22): owner's responsibility, contractor's responsibility, and neither party's responsibility are 2.3 day, 2.2 day, and 0.5 day, respectively.

- $\quad$ Step 16: The result for period (22), as shown in Figure 8, is shown in Table 8.

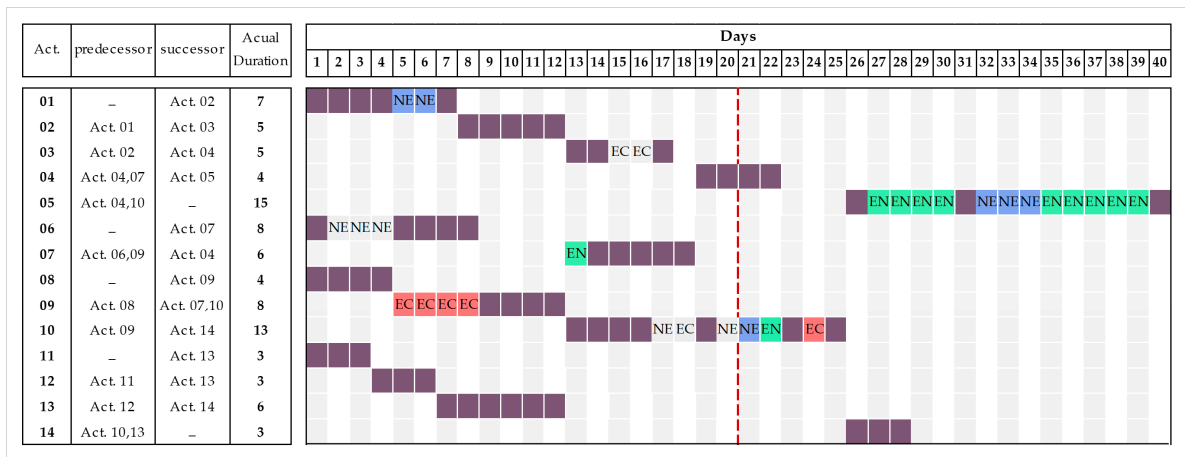

Figure 8. As-planned impacted schedule, period (35-39). 
Table 8. The results of period (35-39) into the project delays.

\begin{tabular}{|c|c|c|c|c|c|c|c|c|}
\hline $\begin{array}{l}\text { PFMD } \\
\text { Periods }\end{array}$ & $\begin{array}{l}\text { Window } \\
\text { Number }\end{array}$ & $\begin{array}{l}\text { Window } \\
\text { Periods }\end{array}$ & $\begin{array}{l}\text { Schedule } \\
\text { Update }\end{array}$ & $\begin{array}{c}\text { Completion } \\
\text { Date }\end{array}$ & EC & $\mathrm{NE}$ & UFMD & PFMD \\
\hline & 0 & 0 & 0 & 20 & 0 & 0 & 0 & - \\
\hline & 1 & $1-5$ & 20 & 21 & 0.5 & 0.5 & 0 & - \\
\hline & 2 & 6 & 21 & 22 & 0.5 & 0.5 & 0 & - \\
\hline & 3 & $7-8$ & 22 & 24 & 2 & 0 & 0 & - \\
\hline & 4 & 9-13 & 24 & 25 & 0 & 0 & 1 & - \\
\hline & 5 & $14-21$ & 25 & 26 & 0 & 1 & 0 & - \\
\hline \multirow[t]{2}{*}{$(22)$} & 6 & 22 & 26 & 27 & 0.7 & 0.3 & 0 & 0 \\
\hline & 7 & $23-26$ & 27 & 28 & 1 & 0 & 0 & - \\
\hline \multirow[t]{2}{*}{$(27-30)$} & 8 & $27-30$ & 28 & 32 & 2.1 & 1.3 & 0.6 & 0 \\
\hline & 9 & $31-34$ & 32 & 35 & 0 & 3 & 0 & - \\
\hline \multirow[t]{3}{*}{$(35-39)$} & 10 & $35-40$ & 35 & 40 & 2.3 & 2.2 & 0.5 & 0 \\
\hline & \multicolumn{4}{|c|}{ Responsibility for project delays } & 9.1 & 8.8 & 2.1 & 0 \\
\hline & \multicolumn{4}{|c|}{ Total project delays } & & 20 & & \\
\hline
\end{tabular}

\subsubsection{The Result}

The proposed method results demonstrate the schedule delays analysis considering the responsibility for PFMD as shown in Table 9. In the proposed systematic method, the analysis result shows 20 days, which is the same number of days of the extension period for the original contract time. However, allocating the responsibility for 20 days of delays differ by considering the PFMD issue. In the proposed method, three periods of PFMDs have been reallocated onto the responsible delays that contributed in extending the contract into PFMD period. This also proves that the cumulative impacts of project delays onto PFMD periods can be measured by the proposed method, resulting in different values compared with Table 1 .

Table 9. The analysis results for the proposed method analysis.

\begin{tabular}{|c|c|c|c|c|c|c|c|}
\hline PFMD Period & $\begin{array}{l}\text { Window } \\
\text { Number }\end{array}$ & $\begin{array}{l}\text { Window } \\
\text { Periods }\end{array}$ & $\begin{array}{c}\text { Schedule } \\
\text { Update }\end{array}$ & $\begin{array}{c}\text { Completion } \\
\text { Date }\end{array}$ & EC & NE & UFMD \\
\hline & 0 (start) & 0 & 0 & 20 & 0 & 0 & 0 \\
\hline & 1 & $1-5$ & 20 & 21 & 0.5 & 0.5 & 0 \\
\hline & 2 & 6 & 21 & 22 & 0.5 & 0.5 & 0 \\
\hline & 3 & $7-8$ & 22 & 24 & 2 & 0 & 0 \\
\hline & 4 & $9-13$ & 24 & 25 & 0 & 0 & 1 \\
\hline & 5 & $14-21$ & 25 & 26 & 0 & 1 & 0 \\
\hline \multirow[t]{2}{*}{ First period } & 6 & 22 & 26 & 27 & 0.7 & 0.3 & 0 \\
\hline & 7 & $23-26$ & 27 & 28 & 1 & 0 & 0 \\
\hline \multirow[t]{2}{*}{ Second period } & 8 & $27-30$ & 28 & 32 & 2.1 & 0.3 & 0.6 \\
\hline & 9 & $31-34$ & 32 & 35 & 0 & 3 & 0 \\
\hline \multirow[t]{2}{*}{ Third period } & 10 & $35-40$ & 35 & 40 & 2.3 & 2.2 & 0.5 \\
\hline & \multicolumn{4}{|c|}{ Responsibility for project delays } & 9.1 & 8.8 & 2.1 \\
\hline
\end{tabular}

In Table 10, the result illustrates that (1) owner's delay (EC) contributed to the overall PFMD periods in 5.1 days; (2) contractor's delay (NE) contributed to PFMD periods in 3.8 days; and (3) force majeure delay that affected Act.07 on day 13 has also contributed to PFMDs and is responsible for 1.1 day. Therefore, the proposed method analysis proves that only 1.1 day out of 10 force majeure delays are unavoidable force majeure delays. Also, the proposed analysis clearly proves that 5.1 days out of ten force majeure delays have resulted from the owner's fault. Without considering the PFMD issue, the contractor would be responsible for the additional costs attributable to the whole of the 
PFMDs. Meanwhile, the impact of the contractor' delays have contributed into 3.8 days of force majeure delays, where the owner also will lose profits due to these delays.

Table 10. The result of the PFMD method.

\begin{tabular}{cccccc}
\hline \multirow{2}{*}{ PFMD Periods } & \multirow{2}{*}{ PFMDs Days } & \multicolumn{3}{c}{ Responsibility of PFMD } & \multirow{2}{*}{ Total } \\
\cline { 3 - 5 } & & EC & NE & EN & \\
\hline$(22)$ & 1 & 0.7 & 0.3 & 0 & \\
$(27-30)$ & 4 & 2.1 & 1.3 & 0.6 & \\
$(35-39)$ & 5 & 2.3 & 2.2 & 0.5 & \\
\hline Responsibility for PFMD & & 5.1 & 3.8 & 1.1 & 10 \\
\hline
\end{tabular}

The final responsibility of project delay analysis by the proposed method is shown in Table 11 . In the proposed method, the critical delays have been determined by the window analysis method. Among the critical delays, the PFMD have been defined by the PFMD method. Thus, ten days of force majeure delay that occurred during the period (22), (27-30) and (35-39) are determined as PFMDs. With PFMD method, daily analysis was employed to continually account for the impact of the project delays to each period of PFMD. Also, the early finish for affected activities was employed to compute the changes and calculate the responsibility for each schedule delay. Therefore, four delays caused the overall project completion by the owner as well as the owner's responsibility for extending the performance into 5.1 days of PFMD. The contractor also caused five delays to the overall project completion as well as extending the performance into 3.8 days of PFMD. The result also shows that, among the critical delays, only one UFMD is a critical delay to the overall project completion and has contributed in pushing the performance into 1.1 day of PFMDs.

Table 11. The final responsibility of project delay analysis by the proposed method.

\begin{tabular}{cccc}
\hline Delay's Responsibility & Critical Delays & $\begin{array}{c}\text { Responsibility for } \\
\text { PFMD Periods }\end{array}$ & Total Responsibility \\
\hline Owner's Delay (EC) & 4 & 5.1 & 9.1 \\
Contractor's Delay (NE) & 5 & 3.8 & 8.8 \\
Neither Party's Delay (EN) & 1 & 1.1 & 2.1 \\
Total project delays & 10 & 10 & 20 \\
\hline
\end{tabular}

\section{Pros and Cons of the Proposed Systematic Method}

The proposed systematic method is the integration of the window analysis method, as the most effective method, with PFMD method. The idea behind this integration was to bring together the benefits of two approaches, where the window method has the capability to calculate the schedule delay and determine the critical delays in more efficiency manner, and the PFMD method has the capability to calculate the responsibility for force majeure delays.

The proposed method offers a very effective approach to minimize force majeure delay claims that resulted from extending the original contract period. This method has the ability to (1) calculate the schedule delays in more accurate results; (2) distinguish the extension period of project contract, so PFMD can be determined; (3) analyze day-by-day the impact of the project delays in pushing the project into PFMD period, so the PFMD responsibility can be also fixed; and (4) solve the mixed responsibilities for causing PFMD.

A major advantage of the proposed method is that it divides a complicated responsibility of PFMD into a manageable one and also takes into account the dynamic nature of the critical path. Also, it has three main benefits. Firstly, the increase of awareness to analysts, contractors, and owners on how the delay contribute into further delays on the schedule, and what the analysis of delay claim can be involved. Secondly, it helps the contracting parties to evaluate the impact of the schedule delay onto 
force majeure delays and protect their right before any economic damages are determined. Thirdly, its approach follows a rigorous and equitable procedure that is bound to produce accurate and valid results acceptable to claims parties.

Although the PFMD method has the potential for calculating the schedule delay responsibility, the calculation of the total project delays would require an effective process to account for other delay issues that have the potential to affect the results, which is beyond the objective of PFMD method. These issues include allocation of each delay responsibility, resolving the concurrent delays and pacing delay, total floats consumption, critical and non-critical delays, loss of productivity and resource allocations. With this integration for proposed systematic method, the project delay can be calculated accurately by the window analysis method as well resolving the responsibility for force majeure delays by the PFMD method, which will hopefully provide an acceptable basis in delay claims and a realistic assessment of contractual liability.

\section{Study Validity and Limitations}

Each delay analysis method has strengths and weaknesses, and therefore requires a series of validation processes together with proper application procedure to guarantee reliable results. Based on this requirement, the reliability and validity of any delay analysis method are best achieved by following the renowned recommended protocol by the American Association of Cost Engineers (AACE) [63]. This protocol provides a comprehensive guidance on forensic schedule analysis methodologies that is widely recognized and used by delay claims experts in the construction industry. The AACE protocol expresses two key principles on the level of accuracy of the results produced by any delay analysis methodology. First, that the best accuracy that analysts can hope to achieve is an objective reflection of the facts as represented in the project documents and data. Second, it considers the level of accuracy as a function of the quality of the data used therein, the accuracy of the assumptions, and the subjective judgments made by the forensic schedule analysts. Therefore, to enhance the validity of the proposed method, the study followed the recommended protocol's requirements so as to ensure its acceptability and practicality amongst practitioners and researchers. The following outlines how these validity measures were employed in this study.

First, the proposed method relies on the appropriate input data which consists of the as-planned schedule, as-built schedule and update schedules, as recommended and detailed in Sections 2.1-2.4 of the AACE protocol [63]. Second, the results of the method are based on daily window analysis, which is highly regarded as a reliable methodology for observing the behavior of the schedule from update to update, and measuring variances to determine the overall project delay [62]. Furthermore, the method's analysis involves the sequential comparison of individual activities' planned finish date with actual finish date to determine the responsibility of each delay in pushing the activity into PFMD period. This comparison was undertaken by using the theory of CPM logic-driven to compare the early finish of impacted activities before and after each delay. This approach has been the principle used as a valid criterion for measuring delay impact by a number of studies (for example [51-61]).

The proposed method involves complex logical processes that would be difficult to handle manually without the aid of a computer program when dealing with real-life construction projects that are often characterized by numerous complexities. It is for this reason that the developed method adopted a simple case study for purposes of illustrating its application process and also demonstrates its practicality. Although the case-study project utilized in this study is a hypothetical project, the scenarios have been constructed to reflect the context and relevance of typical construction delays as closely as possible.

\section{Conclusions}

Delays in completing a construction project can have significant financial impact on the owner and the contractor. Thus, analyzing the responsibility of schedule delays should be conducted in a manner that is equitable to the contracting parties. Currently, when a force majeure delay is involved 
in the project schedule, neither party is entitled to recover the costs of the delay damage. However, there is a situation of force majeure delay that may demand a compensation for the delay damages, due to the contribution of the contracting parties in pushing the project performance to this period of force majeure delay. In other words, the project delays are responsible for extending the original contract period into the occurrence time of force majeure delay. It is thus reasonable to regard this situation as a preventable force majeure delay (PFMD) in the sense that it would not have been an issue had the project been completed within the original contract period.

Although the concept of PFMD has been presented and advanced in legal judicial claims, it is however not popular in practice; this is coupled with the fact that existing DATs have failed to keep pace with resolving this issue. It is also noteworthy that the affected party has the right to claim against any delays that result from the negligence or tardiness of other party, which makes the lack of accounting for PFMD in delay analysis a major gap. Therefore, as an attempt to help minimize disputes involving force majeure claims, this paper presents a systematic method for accurately calculating the schedule delay with thorough consideration of the PFMD issue.

The approach followed in developing the systematic method involving an integration of the process for resolving PFMD issues with the window analysis method. With this integration, window analysis offers the capability to produce more reliable results regarding the total project delays calculations, whilst the PFMD method is able to determine PFMD responsibilities amongst the parties. After developing the method's systematic procedure involved, it was applied to a case-study to demonstrate clarity and robustness of its implementation process.

The result of the case study indicates that the proposed method provides a more logical process for analyzing PFMD situations, where each delay impact affecting the schedule is taken into account in a systematic manner. As the proposed method shows how the schedule led to more delays that can be avoided, which are PFMDs, it also shows how the most PFMDs can be determined and analyzed with more logic process. The proposed systematic method also showed a powerful ability to provide accurate and traceable results. Also, it offers an equitable analysis for the losses during PFMD periods, which have been fairly allocated between the responsible parties. This would raise awareness as to the importance of the analysis delay issues and the improvement needs in delay analysis methods.

Acknowledgments: This research was funded by The Grants Program for Universities and Research Centers (GPURC), King Abdulaziz City for Science and Technology (KACST), Kingdom of Saudi Arabia, Award Number (IT-36-241).

Author Contributions: Saud Alshammari was the primary researcher and responsible for the research design who conducted the majority of the study. Dr. Khalid Al-Gahtani contributed in the research design and revised the paper on several occasions. Prof. Ibrahim A. Alhammad was the principal supervisor who oversaw the research setup. Dr. Nuhu Braimah contributed to this paper by guiding the overall structure and content of the paper, and helping with the final editing.

Conflicts of Interest: The authors declare no conflict of interest.

\section{References}

1. Perera, N.A.; Sutrisna, M.; Yiu, T.W. Decision-making model for selecting the optimum method of delay analysis in construction projects. J. Manag. Eng. 2016, 32, 04016009. [CrossRef]

2. Assaf, S.A.; Al-Hejji, S. Causes of delay in large construction projects. Int. J. Proj. Manag. 2006, $24,349-357$. [CrossRef]

3. Yang, J.B.; Teng, Y.L. Theoretical development of stochastic delay analysis and forecast method. J. Chin. Inst. Eng. 2017, 40, 391-400. [CrossRef]

4. Keane, P.J.; Caletka, A.F. Delay Analysis in Construction Contracts; John Wiley \& Sons: Hoboken, NJ, USA, 2015.

5. Yang, J.B.; Kao, C.K. Critical path effect based delay analysis method for construction projects. Int. J. Proj. Manag. 2012, 30, 385-397. [CrossRef]

6. Burr, A. (Ed.) Delay and Disruption in Construction Contracts; CRC Press: Boca Raton, FL, USA, 2016.

7. Yang, J.B.; Huang, K.M.; Lee, C.H.; Chiu, C.T. Incorporating lost productivity calculation into delay analysis for construction projects. KSCE J. Civ. Eng. 2014, 18, 380-388. [CrossRef] 
8. Birgonul, M.T.; Dikmen, I.; Bektas, S. Integrated approach to overcome shortcomings in current delay analysis practices. J. Constr. Eng. Manag. 2014, 141, 04014088. [CrossRef]

9. Braimah, N. Construction delay analysis techniques-A review of application issues and improvement needs. Buildings 2013, 3, 506-531. [CrossRef]

10. Ridder, P.; Weller, M.P. Unforeseen circumstances, hardship, impossibility and force majeure under German contract law. Eur. Rev. Priv. Law 2014, 22, 371-391.

11. Loulakis, M.C.; McLaughlin, L.P. Contractors Unable to Prove Force Majeure Event Occurred. Civ. Eng. Mag. Arch. 2010, 80, 92. [CrossRef]

12. Chinowsky, P.S.; Price, J.C.; Neumann, J.E. Assessment of climate change adaptation costs for the US road network. Glob. Environ. Chang. 2013, 23, 764-773. [CrossRef]

13. FIDIC's. Conditions of Contract for Construction-Clause 19, 1st ed.; FIDIC: Geneva, Switzerland, 1999; ISBN 2-88432-022-9.

14. Buffalow, G.C. The Force Majeure Defense-Recent Cases, Boilerplate and Analysis. J. Marit. Law Commer. 2011, 42, 211-230.

15. Bramble, B.B.; Callahan, M.T. Construction Delay Claims, 4th ed.; Aspen Publishers: New York, NY, USA, 2010.

16. Department of Transportation Board of Contract Appeals (DOTBCA) Nos. 1669, 1691, 87-1 B.C.A. (CCH). 19,582 at 99,028; Time Contractors, J.V.; DOTBCA: Washington, DC, USA, 1987.

17. DTC Engineers \& Constructors, LLC. Armed Services Board of Contract Appeals, ASBCA No. 57614, 12-1 B.C.A. (CCH) 34967; ASBCA: Falls Church, VA, USA, 2012.

18. Charles, G. Williams Construction, Inc., Armed Services Board of Contract Appeals (ASBCA) No. 42592, 92-1 B.C.A. (CCH) 24,635 at 122,930; ASBCA: Falls Church, VA, USA, 1991.

19. Wright, W.C. Force Majeure Delays. Constr. Law 2006, 26, 33-51.

20. Bruner, P.L. Force Majeure and Unforeseen Ground Conditions in the New Millennium: Unifying Principles and "Tales of Iron Wars". Int. Constr. Law Rev. 2000, 17, 47-101.

21. Rauh, T. Legal Consequences of Force Majeure under German, Swiss, English and United States' Law. Denver J. Int. Law Policy 1996, 25, 151-172.

22. Zack, J.G., Jr. Pacing delays-The practical effect. Cost Eng. 2000, 42, 23-28.

23. Arditi, D.; Robinson, M.A. Concurrent Delays in Construction Litigation. Cost Eng. 1995, 37, 20-30.

24. Ibbs, W., Jr. Key elements of construction specification. J. Am. Water Works Assoc. 1984, 76, 48-55.

25. Arditi, D.; Akan, G.T.; Gurdamar, S. Reasons for delays in public projects in Turkey. J. Constr. Manag. Econ. 1985, 3, 171-181. [CrossRef]

26. Pickavance, K. Delay and Disruption in Construction Contracts, 4th ed.; Sweet \& Maxwell: London, UK, 2010.

27. Hegazy, T.; Zhang, K. Daily window delay analysis. J. Constr. Eng. Manag. ASCE 2005, 131, 505-512. [CrossRef]

28. Peters, T.F. Performing forensic delay analyses from deep within the black tent. AACE Int. Trans. 2007, 2, CDR.01.1-CDR.01.9.

29. Mohan, S.B.; Al-Gahtani, K.S. Current delay analysis techniques and improvements. J. Cost Eng. 2006, 48, $12-21$.

30. Braimah, N. Approaches to delay claims assessment employed in the UK construction industry. Buildings 2013, 3, 598-620. [CrossRef]

31. Polkinghorne, M.; Rosenberg, C.B. The Ebola Epidemic and Force Majeure: Expecting the Unexpected. Altern. High Cost Litig. 2014, 32, 165-178. [CrossRef]

32. Theroux, M.; Grosse, A.D. Force Majeure in Canadian Law. Alta. Law Rev. 2011, 49, 397-425.

33. Eriksen, E. Terrorism and Force Majeure in International Contracts. Bond Law Rev. 2004, 16, 176-199.

34. The International Federation of Consulting Engineers. FIDIC Conditions of Contracts for Works of Civil Engineering Construction 44.1, 4th ed.; FIDIC: Geneva, Switzerland, 1987.

35. The International Federation of Consulting Engineers. FIDIC Conditions Cl., 19.1, MDB ed.; FIDIC: Geneva, Switzerland, 2005.

36. AIA Contract Documents a201-2007. General Conditions for the Contract for Construction; American Institute of Architects: Washington, DC, USA, 2007; Section 8.3.1.

37. The International Federation of Consulting Engineers. FIDIC Conditions of Contract for EPC/Turnkey Projects; FIDIC: Geneva, Switzerland, 1999.

38. Kululanga, G.K.; Kuotcha, W.; McCaffer, R.; Edum-Fotwe, F. Construction contractors' claim process framework. J. Constr. Eng. Manag. 2001, 127, 309-314. [CrossRef] 
39. Yates, J.K.; Epstein, A. Avoiding and minimizing construction delay claim disputes in relational contracting. J. Prof. Issues Eng. Educ. Pract. 2006, 132, 168-179. [CrossRef]

40. Swanson, J.A. The Hand of God: Limiting the Impact of the Force Majeure Clause in an Oil and Gas Lease. NDL Rev. 2013, 89, 224-239.

41. Janku, M. Contractual Penalty and the Right to Payment for Delays Caused by Force Majeure in Czech Civil Law under the New Civil Code. DANUBE Law Econ. Rev. 2015, 6, 259-269. [CrossRef]

42. Saul, R.; Barnes, R.; Elliott, M. Is climate change an unforeseen, irresistible and external factor-A force majeure in marine environmental law? Mar. Pollut. Bull. 2016, 113, 25-35. [CrossRef] [PubMed]

43. Vasilyeva-Lyulina, A.; Onishi, M.; Kobayashi, K. Delay analysis methods for construction projects: Mathematical modelling. Int. J. Transp. 2015, 3, 27-36. [CrossRef]

44. Al-Gahtani, K.S.; Al-Sulaihi, I.A.; Iqupal, A. Total float management: Computerized technique for construction delay analysis. Can. J. Civ. Eng. 2016, 43, 391-401. [CrossRef]

45. Alkass, S.; Mazerolle, M.; Harris, F. Construction delay analysis techniques. Constr. Manag. Econ. 1996, 14, 375-394. [CrossRef]

46. Pinnell, S. How to Get Paid for Construction Changes: Preparation, Resolution Tools and Techniques; McGraw-Hill Companies, Inc.: New York, NY, USA, 1998.

47. Alkass, S.; Mazerolle, M.; Tribaldos, E.; Harris, F. Computer aided construction delay analysis and claims preparation. J. Constr. Manag. Econ. 1995, 13, 335-352. [CrossRef]

48. Korman, R.; Daniels, S.H. Critics can't find the logic in many of today's CPM schedules users want software with flexibility, but is it true CPM. Eng. News Rec. 2003, 250, 30-33.

49. Bubshait, A.A.; Cunningham, M.J. Comparison of delay analysis methodologies. J. Constr. Eng. Manag. ASCE 1998, 124, 315-322. [CrossRef]

50. Stumpf, G.R. Schedule delay analysis. J. Cost Eng. 2000, 42, 32-43.

51. Lucas, D.E. Schedule Analyser Pro-An aid in the analysis of delay time impact analysis. J. Cost Eng. 2002, $44,30-36$.

52. Wickwire, J.M.; Groff, M.J. Update on CPM proof of delay claims. Sched. Update-Proj. Manag. Inst. Coll. Sched. 2004, 1, 3-9.

53. Baram, G.E. The window methods of analyzing delay claims. AACE Int. Trans. 2000, CDR.09.1-CDR.09.6.

54. Al-Gahtani, K.S.; Mohan, S.B. Total float management for delay analysis. Cost Eng. 2007, 49, 32-37.

55. Reams, J.S. Substantiation and use of the planned schedule in a delay analysis. Cost Eng. 1990, 32, 12-16.

56. Alkass, S.; Harris, F. An integrated system that aids in the analysis of contractor's claims resulting from delays. Build. Res. Inf. 1991, 19, 56-64. [CrossRef]

57. Kartam, S. Generic methodology for analyzing delay claims. J. Constr. Eng. Manag. 1999, 125, 409-419. [CrossRef]

58. Shi, J.J.; Cheung, S.O.; Arditi, D. Construction delay computation method. J. Constr. Eng. Manag. 2001, 127, 60-65. [CrossRef]

59. Ng, S.T.; Skitmore, M.; Deng, M.Z.M.; Nadeem, A. Improving existing delay analysis techniques for the establishment of delay liabilities. Constr. Innov. 2004, 4, 3-17. [CrossRef]

60. Kallo, G.G. Reliability of critical path method (CPM) techniques in the analysis and evaluation of delay claims. J. Cost Eng. 1996, 38, 35-37.

61. Finke, M.R. Window analysis of compensable delays. J. Constr. Eng. Manag. ASCE 1999, 125, 96-100. [CrossRef]

62. Society of Construction Law (SCL). Protocol for Determining Extensions of Time and Compensations for Delay and Disruption; SCL: Burbage, UK, 2002; Available online: Http: / www.eotprotocol.com (accessed on 19 July 2013).

63. AACE International. Forensic Schedule Analysis, AACE International Recommended Practice No. 29R-03, TCM Framework 6.4-Forensic Performance Assessment; AACE International: Morgantown, VA, USA, 2007.

(C) 2017 by the authors. Licensee MDPI, Basel, Switzerland. This article is an open access article distributed under the terms and conditions of the Creative Commons Attribution (CC BY) license (http:/ / creativecommons.org/licenses/by/4.0/). 